\title{
In memoriam Professor Dr. John Fernandes
}

\author{
G. Peter A. Smit
}

Received: 12 January 2007 / Revised: 7 May 2007 / Accepted: 10 May 2007 / Published online: 10 July 2007

(C) Springer-Verlag 2007

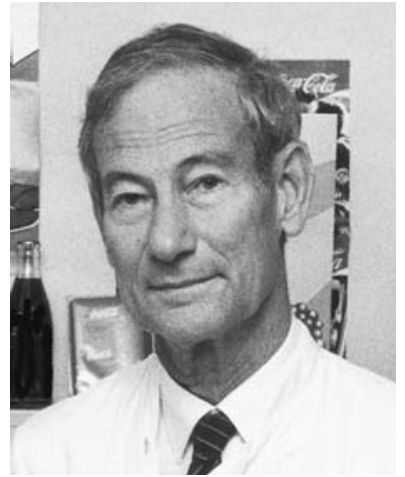

Legend to the picture:

John Fernandes, 1 January 1921-27 December 2006. Photo taken in 1986 at the location of the Beatrix Children's Hospital of the University Medical Centre Groningen.

Obituary:

Dear colleagues, it is my sad duty to inform you that Prof Dr. John Fernandes passed away on 27 December 2006.

John Fernandes was head of the Department of Paediatrics in the University Hospital Groningen from 1978 until 1987.
He was born on 1 January 1921 in Poerwokerto, Indonesia. He graduated with a MD in 1948 at the University of Leiden and earned his $\mathrm{PhD}$ in 1953 at the University of Leiden on a thesis entitled "Fat absorption studied in a child with chylothorax".

Later in his career he continued to work as an Associate Professor in Paediatrics at the Sophia's Children's Hospital and Neonatal Unit, Erasmus Medical Centre, Rotterdam, from 1968-1978.

His main research interest was focussed on paediatric gastro-enterology and inborn metabolic diseases, especially glycogen storage diseases.

He played a crucial role in the initiation and the success of the Groningen Paediatric Liver Transplantation Programme and the development of the paediatric research laboratories in our department.

Even in the period of his retirement he still stayed interested in these fields of research, was a frequent visitor to our department and frequently attended research meetings.

Most of you will know John Fernandes from what was later called "the Fernandes", the book on metabolic diseases entitled "Inborn Metabolic Diseases" of which he was the initiator.

A few months before his death John Fernandes was awarded the prestigious "Gorter penning" from the Dutch Paediatric Association (NVK) in honour of his work.

January 2007

G. P. A. Smit ( $\square)$

Department of Metabolic Diseases, Beatrix Children's Hospital,

University Medical Centre,

Groningen, The Netherlands

e-mail: g.p.a.smit@bkk.umcg.nl 